\title{
El diablo y las brujas: una religiosidad del miedo
}

\section{The Devil and the Witches: a Religiosity of Fear}

\author{
Elia Nathan Bravo $\dagger$
}

El artículo analiza los conceptos de 'demonio' y 'bruja', su estrecha interdependencia y los cambios que estos experimentaron en el periodo que va de los siglos XIV al XVII. El análisis muestra cómo ambos conceptos estuvieron íntimamente relacionados en el pensamiento religioso de Europa Occidental durante el Renacimiento y el Barroco. El análisis profundiza en dos hechos: a) por una parte, la mayor presencia de la figura del demonio en el periodo estudiado, su relación directa con los hombres, particularmente con los brujos, y los tipos de ayuda sobrenatural que ofrecía a estos para que pudieran realizar hechizos, a cambio de que los brujos le juraran fidelidad y le sirvieran en su propósito fundamental de combatir a Dios; b) por otra, la reconceptualización de bruja a partir del siglo Xv, ya que es en este periodo cuando surge en su versión madura, como recreación por parte de teólogos, predicadores y pensadores de la Iglesia católica, y los tipos de hechizos que estas realizaban, tales como, entre otros, enfermar o causar la muerte a personas o a animales, curarlos de sus enfermedades, causar tempestades o pestes que destruyen las cosechas, adivinar el futuro, localizar objetos robados, crear amor o enemistad, etcétera.

Palabras clave: demonio, brujo, brujería, hechizo, iglesia católica, inquisición, teología, renacimiento, barroco

The paper analyzes the concepts of 'demon' and 'wizard' and the changes undergone by them from the $14^{\text {th }}$ to $17^{\text {th }}$ centuries in Western Europe. Both concepts were re-conceptualized into de Catholic Church and have been closely bound together in the Western religious thought during the Renaissance and Baroque periods. The analysis is focused on two aspects: on the one hand, the increasing presence of demon in the studied period, and its relation with wizards, men and women, in order to help them in their sorceries, but always as an exchange of helping demon in its battle against God. On the other hand, the paper analyzes the many types of female wizards and the kinds of sorceries that these made, like to provoke sickness and healing, to cause death, or to foresee the future.

KeYwords: demon, wizard, sorcery, Catholic Church, Inquisition, theology, renaissance, baroque 
$\mathrm{E}$ n este ensayo examinaré dos temas que estuvieron íntimamente relacionados en el pensamiento religioso de Europa occidental durante el Renacimiento y principios de la modernidad (siglos XIV al XVII). Un tema es el de la imagen de la bruja, y el otro el del papel central que desempeñó la figura del diablo en la religiosidad renacentista y moderna.

Los conceptos de bruja y demonio estuvieron íntimamente asociados porque, para el pensamiento religioso de este periodo, no sólo existía el diablo (entendido como un ser con intereses propios), sino que también entraba en relación directa con los hombres, particularmente con los brujos. El diablo les ofrecía a éstos su ayuda sobrenatural para que pudieran realizar daños o hechizos, a cambio de que ellos le juraran fidelidad yle sirvieran en su propósito fundamental de combatir contra Dios y contra todo lo bueno que existe en el mundo. Ahondemos en el concepto de bruja. Este concepto en su forma madura surgió en el siglo Xv y consistió en la idea de que las brujas son capaces de realizar hechizos sólo gracias a un pacto con el Diablo (Kieckhefer, Magic, 196; Klaits, Servants, 26, 50; Russell, Witchcraft, 17, 25; Russell, History, 39; Trevor-Roper, The European, 93; Thomas, Religion, 521). Ejemplos de hechizos son enfermar o causar la muerte a personas o a animales, curarlos de sus enfermedades, causar tempestades o pestes que destruyen las cosechas, adivinar el futuro, localizar objetos robados, crear amor o enemistad, ocasionar que se pierda una guerra, etc.

Este concepto "europeo" de bruja fue un concepto novedoso, desarrollado por los pensadores renacentistas. Para comprender en qué radica su novedad, recordemos que la creencia en la hechicería, o más generalmente, en la magia, ciertamente es de muy viejo cuño: de ella ya se hablaba en Mesopotamia, Egipto, Persia, Grecia y Roma. El elemento novedoso que introdujeron los pensadores renacentistas fue el de interpretar en términos demoníacos la magia. Ellos sostuvieron que las prácticas mágicas, ya sea que éstas tengan consecuencias benéficas o dañinas, sólo son eficaces gracias a la ayuda sobrenatural que el diablo presta al mago. Esta tesis de que las prácticas mágicas utilizaban una causalidad sobrenatural demoníaca la fundamentaron en la cosmovisión tomista-aristotélica, según la cual no existen en el mundo las relaciones causales mágicas de simpatía, antipatía o contagio, sino que toda causalidad es física; de esta cosmovisión se sigue que aquello que los hombres llaman actos mágicos no puede ser sino el resultado de una intervención sobrenatural demoníaca — si la intervención fuese divina se trataría de milagros, los cuales difieren de los actos mágicos por ser realizados por santos, esto es, por personas avaladas por la Iglesia católica.

Es importante notar que el concepto de brujería fue creado por teólogos, predicadores e inquisidores de la Iglesia católica, dado que fueron ellos 
los que sobrepusieron a la creencia popular en la hechicería o magia la idea de que ésta sólo es posible gracias a la ayuda demoníaca (Henningsen, El abogado, 346; Klaits, Servants, 3, 50; Larner, Witchcraft, 3; Russell, Witchcraft, 26). En otras palabras, lo que ellos hicieron fue hacer de las prácticas mágicas populares, que eran básicamente una técnica para controlar el mundo (o sea, para curar, dañar, ser exitoso en el amor, etc.), una religión heterodoxa o herética, pues sostuvieron que las brujas establecían un pacto de fidelidad con el diablo y lo adoraban en reuniones nocturnas llamadas "aquelarres" o "sabbats" así como realizando malas obras. ${ }^{1}$

Con el fin de descubrir las razones religiosas tras la interpretación demoníaca de la magia, así como ahondar en los conceptos de bruja y de diablo, examinemos el texto demonológico más famoso que ha existido. El martillo de las brujas. Para golpear a las brujas y sus herejías con poderosa maza, escrito en el siglo XV por los inquisidores dominicos Heinrich Kraemer y James Sprenger.

El objetivo explícito de El martillo es el de terminar con la brujería: "se debe hablar al pueblo con el fin de hacer odiar el crimen [de la brujería] y para que los jueces sean más ardientes en la venganza del crimen de los renegados de la fe [i.e. de los brujos]" (II, I, XIV, 314). ${ }^{2}$

O sea, El martillo busca dar a conocer la existencia de la brujería con el fin de que el pueblo sepa que esta es ilícita y deje de practicarla, y también para que los jueces eclesiásticos y civiles castiguen con la pena de muerte a aquellos que continúen practicándola.

\footnotetext{
${ }^{1}$ Probablemente el lector experimente ya cierta confusión acerca de quiénes son los brujos: ¿son sólo los magos que hacen maleficios o daños, o son cualquier mago, ya sea que utilice la magia para hacer maleficios o para fines benéficos (como el curar)? El pensamiento de este periodo es ambiguo; por ejemplo, en El martillo generalmente "bruja" refiere a un mago que hace maleficios, aunque este texto aclara ocasionalmente que "bruja" es cualquier mago, benéfico o maléfico (Kraemer y Sprenger, El martillo, 135 [I, IX], 170 [I, XIV], 341-347 [II, II]). Una razón tras este uso ambiguo del concepto de bruja es de orden argumentativo: es más fácil o plausible conectar al diablo con el mago maléfico que con el benéfico. Otra razón es que en este concepto se conjugan dos intereses distintos: el interés del pueblo, que sólo le incomodan los magos cuando estos causan daños, y el interés de las élites cultas a las que les preocupa que existan prácticas mágicas, independientemente de sus consecuencias benéficas o dañinas. El lector probablemente también experimente una confusión acerca del sexo de las brujas. En esta época usualmente se utilizó el término "bruja" porque se pensaba que la mayoría eran mujeres, aunque se reconocía que ocasionalmente los hombres también podían hacer brujerías (Kraemer y Sprenger, El martillo, 325, 332-333 [II, I, XVI]).

${ }^{2}$ Con el fin de abreviar las referencias a El martillo, sólo utilizaré números romanos que se refieren a las partes, cuestiones y capítulos en que se subdivide, en ese orden, dicho texto, y un número arábigo al final que refiere la página.
}

Medievalia 50, 2018, pp. 237-245 
Para lograr este objetivo El martillo establece dos tesis: a) las brujas existen y b) la práctica de la brujería es ilícita por ser herética. Estudiemos cada tesis.

a) El martillo busca demostrar que las brujas sí existen dado que, como lo prueba el famoso decreto eclesiástico del siglo x llamado Canon episcopi, había dentro de la Iglesia católica una corriente que consideraba que la creencia en la brujería era una creencia falsa por ser los hechizos puramente imaginarios (I, I, 37; I, XII. 149; I, XVIII, 189; el texto completo del Canon puede verse en Robbins, Encyclopedia, 75-7, o en Russell, Witchcraft, 76-7). Para demostrar que las brujas sí existen se argumenta en El martillo que i) las brujas requieren de la ayuda del diablo para poder realizar sus hechicerías o daños, y ii) que el diablo prefiere actuar en el mundo a través de las brujas que hacerlo solo. La tesis i) es demostrada, como dijimos, a partir de una cosmovisión aristotélico-tomista según la cual no existen las relaciones causales mágicas de simpatía, antipatía o contagio en el mundo, y por lo cual las brujas requieren de la ayuda sobrenatural del demonio para poder realizar sus hechizos (I, II, 59-60; II, II, VI, 398-400). La tesis ii) es justificada en El martillo destacando que el diablo prefiere actuar a través de las brujas porque así puede hacer más daño. Para entender esto hay que notar que El martillo tiene una concepción particular del diablo, como un ser sumamente poderoso, casi tanto como Dios, y que está en guerra contra Dios y su creación, el hombre (I, III, 66; II, I, XV, 319). Dada esta concepción, resulta claro que el diablo daña más a Dios actuando a través de las brujas porque, a cambio de ayudarlas a cometer hechizos, las obliga a renegar de Dios, con lo cual logra apropiarse de las criaturas que le pertenecen a Dios, ofendiéndolo así gravemente (II, I, II, 226; II, I, VII, 267; II, I, XI, 293). El diablo logra dañar más a los hombres actuando a través de las brujas porque de esta manera alcanza la perdición eterna de las brujas (I, II, 55; II, II, VII, 404), además de que logra aumentar el número de los que no obtienen la salvación eterna en tanto que al tener relaciones sexuales con los brujos puede robarles su semen y posteriormente depositarlo en una bruja, produciendo así personas que nacen marcadas por la señal de la impureza y viven siempre inmersas en el mal (II, I, IV, 247; I, III, 68-69).

En síntesis, según El martillo las brujas sí existen porque el diablo existe y prefiere actuar a través de ellas, y porque los hechizos sólo son posibles por la ayuda que el diablo les presta. Como puede verse en esta argumentación, la demostración de la existencia de las brujas parte de la doctrina cristiana de que Dios y el diablo existen. Sin embargo, es crucial notar que no toda doctrina cristiana implica la existencia de las brujas, sino sólo aquella que tiene 
una concepción particular del diablo: una concepción relativamente dualista e inmanentista del diablo (Russell, Witchcraft, 66). Según ésta, el diablo es un ser independiente de Dios por tener intereses propios tales como el entrar en guerra con Dios y el hombre; es también un ser casi tan poderoso como Dios porque puede luchar contra Él y, finalmente, es un ser inmanente al mundo porque constantemente está presente en él convenciendo a las personas a convertirse en brujas, ayudándolas a realizar hechizos, teniendo relaciones sexuales con ellas, presidiendo sus aquelarres, etc. ${ }^{3}$ En verdad, la imagen religiosa que proyecta El martillo es la de un mundo en que los hombres encuentran con mayor facilidad al diablo que a Dios.

Ahora bien, en un intento por contrarrestar esta imagen con tintes dualistas del diablo, El martillo sostiene que el diablo sólo puede actuar en el mundo gracias a la permisión divina (I, I, 35-6, 46; I, III, 69; I, XII, 151). En efecto, en El martillo se dice que Dios permite al diablo y a las brujas realizar maleficios porque así se venga del mal ya que éstos recaen usualmente sobre los pecadores, o bien, porque así prueba a los buenos: el soportar con paciencia el daño inmerecido les permite aumentar su mérito ante Dios (I, XV, 176177). Ciertamente esta concepción del diablo como instrumento de Dios para castigar a los malos y probar a los buenos es monoteísta; sin embargo, no es ésta la concepción del diablo que básicamente se maneja en El martillo. Como hemos visto, la tesis de que las brujas existen porque el diablo prefiere actuar a través de ellas presupone una concepción de tinte dualista del diablo (como un ser que tiene fines propios, contrapuestos a Dios, y un gran poder para ser capaz de llevarlos a cabo), y presupone también una concepción un tanto inmanentista del diablo (en cuanto que él es pensado como un ser que constantemente interactúa con las brujas).

b) La otra tesis importante que se establece en El martillo es que la brujería es ilícita por ser herética. Esta tesis es argumentada estableciendo, por una parte, que las brujas requieren de la ayuda del demonio para poder realizar sus maleficios y, por otra parte, que el diablo, a cambio de ayudar a las brujas, les exige que renuncien a Dios y que lo adoren a él en alma y cuerpo. Esta segunda afirmación la demuestra El martillo notando, por un lado, que como el diablo no tiene ningún rasgo de bondad, no ayudaría desinteresadamente a

\footnotetext{
${ }^{3}$ Esta concepción del diablo no es netamente dualista (sólo tiene tintes dualistas) porque él es concebido como un ser creado por Dios - en cambio, para las religiones dualistas (como el gnosticismo, el maniqueísmo o el catarismo) el diablo es un ser o principio absolutamente independiente de Dios, y que junto con Él crea el mundo.
}

Medievalia 50, 2018, pp. 237-245 
las brujas. Por otro lado, el diablo no puede ser coercionado por las brujas para que él las ayude - como pretendían un cierto tipo de magos llamados "nigromantes"- dado que el diablo es un ser espiritual que no puede ser obligado por entes inferiores a él, como son los hombres (II, II, V, 380; II, II, VI, 400). Excluidas estas dos posibilidades, sólo resta que el diablo ayude a las brujas a cambio de algo que a él le convenga, o sea, a cambio de un pacto en que las brujas renuncien a Dios y prometan adorarlo y servirlo a él (II, I, XIV, 314). Es por establecer este pacto de fidelidad con el diablo, o sea, por errar obstinadamente en las cosas de la fe, por lo que las brujas son herejes (I, I, 39; III, 422), o más precisamente, apóstatas que reniegan totalmente de su fe católica (I, XIV, 168-169,171; III, 423). Hemos visto así que en El martillo se argumenta que las brujas sí existen y son herejes, esto es, que las hechiceras para poder realizar sus encantamientos requieren establecer un pacto de fidelidad con el diablo para que éste las ayude. Hemos dicho también que esta interpretación de la hechicería en términos diabólicos fue realizada por los teólogos, predicadores e inquisidores. Cabe preguntarse por qué se desarrolló esta interpretación, y la cacería de brujas a la que dio lugar (o con la que estuvo asociada). $\mathrm{Si}$ bien la respuesta es muy compleja y poco clara, quisiera señalar aquí dos razones de tipo religioso.

Una razón bastante obvia es que al hacer de la magia popular una forma de herejía, y al perseguirla como tal, lo que las élites cultas buscaban era purificar la fe o mantener una ortodoxia - en el caso de la brujería de lo que se trataba era de purificar la religiosidad popular atacando las creencias y prácticas mágicas con las que estaba asociada. Por ser obvia, o clásica, no ahondaré en esta razón.

Veamos otra razón religiosa que aparece mencionada en El martillo. En este texto se afirma que "de los males causados por las brujas frecuentemente se derivan una multitud de ventajas para los fieles: la fe se refuerza, se manifiesta la misericordia de Dios, los hombres actúan para ponerse a la defensa, se muestran más ardientes en la veneración de la pasión de Cristo y de las ceremonias de la Iglesia" (II, I, 205). Aquí se sugiere que es el miedo a los daños que causan las brujas, o más correctamente, a los males que causa el demonio a través de las brujas, lo que acrecienta o refuerza la religiosidad. Este acrecentar la religiosidad ha de entenderse en dos sentidos: a) refuerza o aumenta la adhesión formal a la Iglesia y sus ceremonias, y b) hace más ardiente la fe, la vivencia espiritual. Estudiemos cómo el mecanismo del miedo acrecienta la religiosidad en cada uno de estos dos sentidos. El miedo a las brujas, o al diablo, acrecienta la adhesión formal a una serie de prácticas religiosas porque estas impiden ser hechizado, o bien curan los hechizos. Cito El martillo: 
Una mujer dijo que el Diablo tuvo poder sobre ella por no darse a la oración ni frecuentar los sacramentos, aunque era honesta (I, XI, 40).

El alcalde de Weisenthal dijo protegerse cada domingo tomando sal y agua bendita, pero un domingo no lo hizo y cayó embrujado (II, I, 205).

Las brujas confiesan verse entorpecidas por los ritos de la Iglesia como son la aspersión de agua bendita, el cirio del día de la Purificación, la señal de la cruz (II, II, VII, 403).

La Iglesia también recomienda para los embrujados el exorcismo y las peregrinaciones (II, II, 341).

En relación con el uso del miedo a las brujas como un mecanismo para acrecentar la fe (entendida como vivencia espiritual y no como mera adhesión formal a ciertas creencias o prácticas), destaquemos que una idea central en El martillo es que sólo Dios nos salva del diablo y de las brujas, de tal forma que mientras más aumente el miedo a ellos, más aumentará la búsqueda de Dios. Este mecanismo de reforzar la fe mediante el exacerbar el miedo al diablo, o a las brujas, o al pecado, lo encontramos mencionado en varias ocasiones en El martillo. Por ejemplo, se dice que "las mismas angustias de la tentación de la carne le hicieron más ardiente en la práctica de la oración” (II, I, 209), o bien, en la afirmación de que Dios le permite al diablo arrastrar a las brujas al pecado porque así se muestra la gracia de Dios, ya que la existencia del pecado nos hace acudir a Dios, que es el único que puede salvarnos del pecado (I, XII, 155; I, XIII, 159,162).

Considero que este mecanismo de acrecentar la religiosidad a través del miedo a las brujas o al diablo es una de las razones religiosas tras la interpretación demoníaca de la hechicería. En efecto, ¿qué mejor manera de insistir en la necesidad de una religiosidad intensa que la de enfatizar la existencia de un diablo sumamente poderoso y maligno que constantemente está presente en el mundo creando daños a través de las brujas, y del cual sólo Dios nos puede salvar?

Es interesante notar que este mecanismo de acrecentar la fe mediante el miedo al diablo se encuentra presente en otros casos. Por ejemplo, en los movimientos carismáticos de las varias religiones o iglesias cristianas contemporáneas en las que a la par de una búsqueda intensa de Dios y un énfasis en los dones sobrenaturales como el don de lenguas o el don de curar que Él confiere, se destaca de sobremanera el poder, malignidad y presencia terrena del diablo. Más generalmente, puede decirse que el mecanismo básico es el del miedo, ya sea miedo al demonio, a las brujas, al castigo o a alguna otra cosa. Este mecanismo ha sido utilizado periódicamente por la Iglesia cristiana. Por ejemplo, ya san Agustín en 
el siglo v lo afirmó, aunque en la vertiente del miedo al castigo. Él propuso (y la Iglesia lo llevó a cabo por lo menos hasta el siglo XvII) que los herejes debían ser castigados porque el miedo al castigo (o al dolor que este produce) era un medio eficaz para la conversión a la verdadera fe: "Pero si bien son mejores los que se dirigen [a Dios] por el amor, son muchos más los que se corrigen por el temor", por ello dicen las Sagradas Escrituras: "Con palabras no se enmendará el siervo obstinado, aunque comprenda, no obedecerá" (Prov. 29, 19), (San Agustín, Obras, xia, 467, Epístola 185, vi, 21). ${ }^{4}$

Para concluir quisiera sugerir algunos defectos o peligros que puede presentar el mecanismo de reforzar la fe mediante el exacerbar el miedo al demonio. En primer lugar, considero que la imagen de Dios que de tal mecanismo surge es un tanto negativa. En efecto, parecería ser que Dios sólo existe o tiene sentido gracias al diablo: únicamente porque existe el diablo es necesario que exista un Dios que nos salve de él, que nos salve de los daños, o del pecado, o en general, del mal. Ciertamente ésta es una imagen de Dios bastante distinta a su imagen positiva según la cual Él es la fuente de la creación, de todo lo bueno que existe, del amor y la misericordia, etc.

En segundo lugar, pienso que este mecanismo de reforzar la fe mediante el miedo al diablo puede dar lugar a una actitud vital negativa, a una actitud en que lo que predomina es el miedo al mal o el rechazo obsesivo al mal. Cabe notar que esta actitud de miedo al demonio, o al mal, o al pecado, no es lo equivalente a la actitud de amor a Dios o a la virtud: ${ }^{5}$ hay una gran distancia entre el acercarse a Dios con el fin de que Él nos salve del mal y el acercarse a Dios para agradecerle todo lo bueno que Él creó, encontrando en ello las fuerzas para luchar contra el pecado y para aceptar la inevitabilidad de ciertos males sin que esto nos hunda en la desdicha. En otras palabras, pienso que este mecanismo puede dar lugar a una fe angustiada y culpógena en la que lo que predomina es la actitud de miedo y rechazo al mundo, cuando aparentemente

\footnotetext{
${ }^{4}$ Con el fin de no distorsionar el pensamiento de san Agustín, conviene destacar que para él el temor es un método parcial que debe ser complementado con la instrucción religiosa para ser eficaz, o sea para lograr un cambio de fe, y no una mera adhesión formal a la Iglesia (Obras, viII, 693 [Epístola 100, 2]). Él sostuvo que el miedo es un método parcial porque sólo remueve los obstáculos como la pereza, la costumbre, los lazos familiares o las tendencias innatas al mal, que impiden una verdadera conversión espiritual (Obras, viII, 597, Epístola 93, I, 3; 615, Epístola 93, v, 17).

${ }^{5}$ San Agustín habla de esta no equivalencia entre el miedo y el amor de manera magistral: "En vano se tiene por vencedor del pecado quien no peca [sino] por temor al castigo. [...] Enemigo es pues de la justicia quien no peca por temor al castigo; sólo es amigo de ella quien por su amor no peca” (Obras, XIa, 35-6, Epístola 145, 4).
}

Medievalia 50, 2018, pp. 237-245 
es posible una fe en que predomine la celebración de la creación divina y la actitud vital sea de amor y de misericordia.

Finalmente, en tercer lugar, este mecanismo de reforzar la fe mediante el miedo al diablo puede ser un tanto peligroso dado que puede llegar a ser tan intenso u omniabarcante el miedo al diablo que nos impida el acercamiento a Dios.

He hablado de tres peligros en que se puede caer al utilizar este mecanismo del miedo al diablo. Sin embargo, también cabe la posibilidad de que este mecanismo sea religiosa o espiritualmente benéfico: hablar del diablo y tenerle miedo puede ser una manera simbólica de expresar nuestras tendencias destructivas y nuestro miedo a ellas. Todas estas son posibilidades en el mundo humano, en el que lo que es veneno para unos, es medicina para otros.

\section{BIBLIOGRAFÍA}

Agustín, San, Obras de san Agustín, tomo viII, Madrid: BAC, 1958.

Agustín, San, Obras de san Agustín, tomo xia, Madrid: BAC, 1972.

Henningsen, Gustav, El abogado de las brujas. Brujería vasca e Inquisición española, Madrid: Alianza Editorial, 1983.

Kieckhefer, Richard, Magic in the Middle Ages, Cambridge: Cambridge University Press, 1989.

KLAits, Joseph, Servants of Satan. The Age of The Witch Hunts, Bloomington: Indiana University Press, 1985.

Kraemer, H. y J. Sprenger, El martillo de las brujas. Para golpear a las brujas y sus herejías con poderosa maza, Madrid: Ediciones Felmar, 1976 (Colección Abraxas, 9).

Larner, Christina, Witchcraft and Religion. The Politics of Popular Belief, Oxford y New York: Basil Blackwell, 1984.

Robbins, Rossell Hope, The Encyclopedia of Witchcraft and Demonology, New York: Bonanza Books, 1981.

Russell, JefFrey Burton, Witchcraft in the Middle Ages, Ithaca y London: Cornell University Press, 1972.

Russell, Jeffrey Burton, A History of Witchcraft. Sorcerers, Heretics and Pagans, London: Thames and Hudson, 1980.

Thomas, Keith, Religion and the Decline of Magic. Studies in Popular Belief in Sixteenth and Seventeenth-Century England, Middlesex: Penguin Books, 1980.

Trevor-Roper, H. R., The European Witch-Craze of the Sixteenth and Seventeenth Centuries and Other Essays, New York: Harper Torch-Books, 1969.

Medievalia 50, 2018, pp. 237-245 
